\title{
O Pró-Saúde da Universidade Federal de São Paulo - Contribuições para Institucionalização e Integração Universidade/Serviços de Saúde
}

\author{
The Educational Program for Health Work at \\ the Federal University in São Paulo: \\ Contributions to Institutionalization and \\ Integration between the University and \\ Healthcare Services
}

\author{
Rosana Fiorini Puccini \\ Maria Cristina Gabrielloni \\ Clara Regina Brandão de ÁvilaI \\ Elisabeth Niglio de Figueiredo ${ }^{I I}$ \\ Rosemarie Andreazza \\ Renato NabasVentura
}

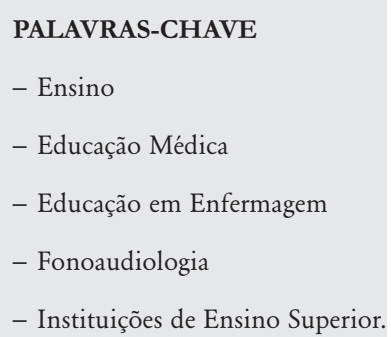

KEYWORDS

- Teaching

- Medical, Education

- Education, Nursing

- Speech, Language and Hearing Sciences

- Higher Education Institutions

Recebido em: 06/10/2010

Aprovado em: 19/11/2010

$80 \frac{\text { REVISTA BRASILEIRA DE EDUCAÇÃO MÉDICA }}{36(1, \text { Supl. 2) } 80.88: 2012}$
${ }^{I}$ Universidade Federal de São Paulo, São Paulo, SP, Brasil.

"I Secretaria Municipal da Saúde de São Paulo, São Paulo, SP, Brasil; Universidade Federal de São Paulo, São Paulo, SP, Brasil. 


\section{INTRODUÇÃO}

Em 2001, foram editadas as Diretrizes Curriculares Nacionais para o ensino de graduação das profissões de saúde, dentre elas Medicina, Enfermagem e Fonoaudiologia. A partir dessas diretrizes, definiu-se as competências para cada área e estabeleceu-se a necessidade de utilização de novas metodologias de ensino-aprendizagem, destacando-se a importância da ampliação do desenvolvimento de atividades práticas nos serviços de saúde, além do Hospital Universitário ${ }^{1}$. Posteriormente, iniciativas como o Promed (Medicina) ${ }^{2}$ e o Pró-Saúde (para os 14 cursos de graduação da área da saúde) ${ }^{3,4}$ foram implementadas pelo Ministério da Educação e da Saúde, com o objetivo de induzir mudanças curriculares que incluam a rede de serviços de saúde para desenvolvimento de atividades práticas, sobretudo na atenção básica à saúde, além de mudanças pedagógicas que favoreçam a integração entre o ciclo básico e clínico e as metodologias ativas de ensino-aprendizagem.

A elaboração dos projetos Pró-Saúde da Medicina e Enfermagem (2005) e Fonoaudiologia (2007) da Universidade Federal de São Paulo considerou o processo articulado que se desenvolvia junto ao Promed, o qual envolvia as comissões de cada um desses cursos e as representações das pró-reitorias de graduação, extensão, pesquisa e pós-graduação da Universidade5. A instituição acumulava experiência com a articulação que se desenvolvia no município de Embu, desde 1969, e em São Paulo, desde os anos 1980. Assim, além da sua comissão gestora," que contava com representação da Universidade e dos serviços de saúde, cuja atuação estava voltada principalmente para as mudanças curriculares e ampliação dos cenários de práticas, o Promed definiu a criação do Núcleo de Educação Permanente e de Pesquisa.O núcleo foi constituído por representantes de todos os cursos da saúde do campus São Paulo, gestores e profissionais dos serviços; sua finalidade era incentivar o desenvolvimento de ações conjuntas na educação permanente e na pesquisa nesses serviços. Essa experiência, somada à aprovação dos projetos Pró-Saúde Medicina, Enfermagem e Fonoaudiologia, fortaleceu o desenvolvimento de ações integradas, não apenas pelo adicional de recursos, mas, sobretudo, devido à ampliação da discussão para elaboração e execução dos projetos envolvendo maior número de docentes e órgãos colegiados da Universidade, consolidando a articulação já estabelecida. Nesse relato de experiência, serão abordadas as principais estratégias que visaram à institucionalização das ações do Pró-Saúde na Universidade e nos serviços de saúde, com o objetivo de garantir sua consolidação e continuidade, como também serão observados seus principais desafios, considerando os contextos políticos da Região
Metropolitana de São Paulo e os modelos de assistência e de gestão adotados.

\section{A Gestão do Pró-Saúde - Planejamento e Acompanhamento do Projeto}

As comissões definidas para gerenciamento das ações do Promed e, posteriormente, do Pró-Saúde Medicina e Enfermagem (2003 a 2006) - Comissão Gestora do Promed/Pró-Saúde e Núcleo de Educação Permanente e Pesquisa - apresentaram algumas limitações apontadas nos processos avaliativos do projeto. Isso fez com fosse necessária a definição de novos espaços de discussão que abordassem algumas questões que não encontravam espaço para diálogo e resolução, gerando impasses e desencontros. Dentre essas questões, destacam-se: o desenvolvimento e detalhamento das atividades no seu cotidiano; a articulação dos docentes coordenadores/supervisores das unidades curriculares que atuam nos serviços de saúde e os profissionais desses serviços (preceptores/gerentes); e a responsabilidade da execução de ações estabelecidas em relação à educação permanente e a pesquisas. Com o objetivo de superar essas dificuldades e atender às novas exigências do Pró-Saúde, foi definido um novo organograma e criadasnovas comissões, as quais são descritas a seguir.

a. Comissão de Acompanhamento Local - constituída a partir da Comissão Gestora do Promed, essa comissão passou a contar com: representantes docentes e discentes das comissões dos cursos de Medicina, Enfermagem, Fonoaudiologia, Tecnologia Oftálmica, Farmácia (novo curso da Unifesp oferecido nocampus Diadema); coordenação do Pet-Saúde; representantes das pró-reitorias de graduação, extensão e pós-graduação; coordenadores das comissões/núcleos de articulação universidade-serviços de saúde de cada município; representantes dos serviços de saúde; e representantes dos usuários dos municípios envolvidos - Embu, São Paulo e Diadema. Esta comissão realiza reuniões mensais e define as diretrizes gerais do projeto, o plano de atividades, a aplicação dos recursos e aprovação dos relatórios. Todas as decisões são estabelecidas de forma articulada com as comissões dos cursos envolvidos nos projetos.

b. Núcleo de Articulação Universidade-Serviços de Saúde/São Paulo - criado em 2006, éconstituído por todos os coordenadores das unidades curriculares dos cursos de Medicina, Enfermagem e Fonoaudiologia que atuam nos serviços de saúde; gerentes das unidades de saúde envolvidas; representantes das comissões dos cursos; representantes de alunos e de usuários. É nesse espaço que o detalhamento das atividades é estabelecido com a participação e contribuição de todos (dias da semana, horários, número de alunos, atividades, área físi- 
ca, salas, etc.). Vale ressaltar que foi este núcleo que definiu os serviços do município de São Paulo a serem integrados no Pró-Saúde, por meio de visita realizada por uma comissão que incluía docentes, alunos e representantes dos usuários. A coordenação deste núcleo compõe a Comissão de Acompanhamento Local do Pró-Saúde. ${ }^{6,7}$

c. Comissão do Pida/Embu -com a ampliação dos departamentos e áreas com atividades a serem realizadas emEmbu, ocorrida em 1982, foi criada a Comissão de Coordenação do Programa de Integração Docente-Assistencial do Embu/ Unifesp. Essa comissão é constituída por docentes representantes dos departamentos que atuam no município - Pediatria, Psiquiatria, Fonoaudiologia, Enfermagem, Oftalmologia/ Tecnologia Oftálmica e Medicina Preventiva. Ela articula as atividades de ensino (unidades de saúde envolvidas, dias da semana, salas disponíveis), assistência e pesquisa junto à Secretaria Municipal de Saúde de Embu, por meio de sua participação em comissões gestoras.Desde a criação do Conselho Municipal de Saúde de Embu, em 1991, a Unifesp tem representação no referido conselho. A coordenação da Comissão do Pida/Embu compõe a Comissão de Acompanhamento Local do Pró-Saúde.

d. Comissão do Pida/Diadema -possui a mesma finalidade do Pida/Embu. Após assinatura do convênio entre a Universidade e aprefeitura de Diadema, foi criada,em junho de 2010, uma comissão para desenvolvimento e detalhamento das atividades em Diadema (unidades/serviços de saúde a serem incluídas nas atividades de alunos, profissionais, horários de funcionamento), agregando docentes de cada curso/ departamento da Universidade e do município. A coordenação da Comissão do Pida/Diadema compõe a Comissão de Acompanhamento Local do Pró-Saúde.

e. Comissão de Educação Permanente e Comissão de Apoio ao Desenvolvimento de Pesquisas no SUS - essas duas comissões recém-criadas têm como finalidade substituir o Núcleo de Educação Permanente, que atuou de 2003a 2006, com base em amplo processo de avaliação de suas atividades, o qual é descrito a seguir.

O Núcleo de Educação Permanente e Pesquisa do Promed foi fundamental no período de sua atuação (2003-2006). Nele há de se destacar, a realização de cursos demandados dos serviços de saúde, dentre os quais se pode citar o de Metodologia Científica, cujo desdobramento resultou na elaboração de projetos de pesquisa, cuja equipe era composta por profissionais de saúde e dos serviços de saúde.Parte desses projetos foi realizada e concluída contando, inclusive, com financiamento de órgãos de fomento. Posteriormente, com a criação dos Polos de Educação Permanente como política do Ministério da Saúde, esse núcleo do Promed/Pró-Saúde manteve-se com o propósito de responder a demandas específicas dos locais de atuação, quenão eram contemplados pelos polos, pois estes respondiam às necessidades regionais. Nesse momento, surgiram algumas dificuldades, porque muitos docentes que desenvolviam atividades de ensino com alunos em serviços de saúde já estavam envolvidos no processo dos Polos de Educação Permanente, restando pouca disponibilidade para a atuação, mais pontual e não remunerada, do Promed/Pró-Saúde. Em relação às pesquisas, após a realização de um seminário, em 2006, para apresentação de projetos a serem desenvolvidos (desdobramento do curso de Metodologia Científica) e dos resultados daqueles já concluídos, definiu-se por ampliar a discussão junto à Pró-Reitoria de Pesquisa e Pós-Graduação, o que só foi possível nos anos de 2009 e 2010.

Assim, como continuidade e buscando maior envolvimento institucional, a partir de 2008 foi realizado um trabalho junto a essas duas pró-reitorias - de Extensão e Pesquisa e de Pós-Graduação. Como resultado, foi aprovada a destinação de vagas dos cursos lato sensu para profissionais dos serviços que atuam nas áreas dos projetos Pró-Saúde, cujo processo será coordenado pela Comissão de Acompanhamento Local. Na Pró-Reitoria de Pós-Graduação e Pesquisa, foi criada uma comissão constituída por representantes de programas das grandes áreas (Saúde Coletiva; Clínica; Pediatria; Ginecologia; Obstetrícia; Psiquiatria; Fonoaudiologia; e Enfermagem) com a finalidade de responder às demandas dos serviços e buscar o desenvolvimento de projetos abrangentes e articulados a eles. Vê-se claramente que há uma produção no âmbito do SUS, ainda que esta não esteja sistematizada. ${ }^{8,9}$ Esta será a oportunidade de um trabalho mais propositivo, no sentido de apoiar, organizar e estruturar trabalhos conjuntos. No $2^{\circ}$ semestre de 2010, foram realizados seminários sobre Educação Permanente e Pesquisa, que contaram com a participação de aproximadamente 200 pessoas (docentes, profissionais da Universidade e dos serviços de saúde) e, a partir desses eventos, além de iniciativas já em andamento (cursos, mestrado profissional, profissionais já matriculados em programas de pós-graduação) favorecidas por todo oprocesso de aproximação institucional com osmunicípios, foram apontadas novas propostas que deverão ser implementadas futuramente. Vale destacar que é a primeira vez que se articula formalmente na Pró-Reitoria de Pesquisa e Pós-Graduação da Universidade uma comissão com a finalidade de apoiar e estimular o desenvolvimento de projetos de pesquisa visando a contribuir para a consolidação do Sistema Único de Saúde incluindo programas das áreas clínicas. 
Como estratégia importante de aproximação e articulação com os serviços de saúde, desde 2005, tem sido realizados, anualmente, de um a dois encontros entre a Universidade e serviços de saúde, com temas que buscam abordar questões atuais e desafios da articulação ensino/serviços de saúde. Cada um desses eventos (foram realizados oito encontros: sete em São Paulo e um em Embu, este em comemoração aos 40 anos do programa) tem contado com a participação de 100 a 200 pessoas entre professores, profissionais da Universidade e dos serviços de saúde, gestores, estudantes, usuários. Nesses encontros, são apresentados trabalhos dos estudantes elaborados em seus estágios curriculares, em projetos de extensão, no Pet-Saúdee na iniciação científica realizada nos serviços de saúde. Alguns dos temas já abordados nesses encontros foram: "Encontro dos Serviços de Saúde com a Universidade: conhecendo os cenários de ensino-aprendizagem" (2007)10; "Encontro Itinerante - 12 encontros com profissionais, usuários, docentes e alunos realizados em cada um dos serviços definidos como cenário de ensino-aprendizagem" (2007); “Integração universidade-serviços de saúde: reafirmando compromissos" e "I Mostra de trabalhos" (2008); "7ํㅡ Encontro Universidade-Serviços de Saúde: reorientação profissional da teoria à prática" e "II Mostra de trabalhos" (2009).

O funcionamento regular da Comissão de Acompanhamento Local, articulado às demais comissões, núcleos e envolvimento com a estrutura da Universidade - pró-reitorias e comissões de cursos, com participação efetiva dos representantes dos municípios e de usuários, garantiu o reconhecimento dessa comissão como espaço de participação e decisões na Universidade e nos serviços de saúde, o que tem sido fundamental para o desenvolvimento dos projetos. Temas e questões relacionadas à integração com serviços de saúde, mesmo que não previstos no projeto Pró-Saúde, são demandas dessas duas instâncias, demonstrando que oorganograma e fluxo definidos constituem um legado político do Pró-Saúde.

\section{Avaliação - Avanços e Retrocessos}

A atuação em serviços de saúde externos ao hospital universitário já ocorria há muitos anos na Unifesp com diferentes formatos, objetivos e arranjos. Porém, é a partir do projeto Pró-Saúde que essa questão passa a ser incluída como ponto relevante na agenda da Universidade, a qual se coloca com grande empenho no estabelecimento dos convênios com serviços de saúde do município de São Paulo e, mais recentemente, do município de Diadema (emEmbu isso já ocorria desde os anos 1970). Em São Paulo, algumas atividades anteriormente desenvolvidas de forma dispersa ou pontual, sem um território definido e com base na informalidade, passam a compor pla- nos de trabalho, com local definido de forma compartilhada entre os gestores do curso/unidades curriculares e gerentes / profissionais dos serviços de saúde.Além disso, o compromisso da Universidade com a educação permanente e a produção de conhecimento também se dá de forma compartilhada.

Como avanços incluem-se: a experiência das comissões docentes/alunos para visitas às unidades de saúde e participação em conselhos gestores das unidades, visando à identificação dos serviços que oferecem maiores possibilidades de atuação, bem como definição das atividades ${ }^{6,7}$; o envolvimento de docentes e profissionais no desenvolvimento de unidades curriculares interdepartamentais ${ }^{11}$; o desenvolvimento de uma unidade curricular que inclui alunos de dois cursos (Medicina e Fonoaudiologia); a integração e definição do eixo da saúde coletiva no curso de Medicina (discutida desde a implantação do currículo nuclear, em 1997), somente concretizada a partir de 2006, o que em grande parte foi decorrência do processo de discussão do Pró-Saúde; a ampliação efetiva das atividades de ensino-aprendizagem em Unidades Básicas de Saúde; a definição conjunta de territórios para atuação articulada (Medicina, Enfermagem, Fonoaudiologia, Tecnologia Oftálmica e, mais recentemente, Farmácia). Todo o processo de organização do Pró-Saúde, seu organograma com espaço de participação e articulação, é considerado um dos maiores avanços do projeto, potencialmente capaz de garantir sua continuidade. Um exemplo é o instrumento de avaliação criado pelo Núcleo de Articulação Universidade/Serviços de Saúde para todos os segmentos - estudantes, usuários, gerentes. Esse instrumento já foi aplicado aos gestores e docentes (dimensões: físico-funcional, pedagógica, cuidado, gestão) e foiimplementado entreos profissionais noano de 2010. Foram também definidos indicadores para cada eixo dos projetos Pró-Saúde, considerando:

- mudança na carga horária da graduação nos serviços de saúde, participação de professores na atividades, produção científica na área, Pibics, participação da instituição em eventos com apresentação de trabalhos;

- número de estudantes em projetos de extensão;

- ampliação da porcentagem de carga horária prática nos cursos de graduação;

- ampliação da carga horária de unidades curriculares desenvolvidas em conjunto com outros cursos;

- ampliação da carga horária em unidades básicas de saúde e nos serviços de saúde;

- número de projetos de pesquisa;

- número de pós-graduandos - mestrandos e doutorandos;

- número de projetos de iniciação científica; 
- número de cursos e de profissionais envolvidos nos processos de educação permanente;

- apresentações em congressos - trabalhos e experiências;

- número de resumos publicados em anais e revistas;

- número de artigos submetidos, aceitos e publicados em periódicos.

Quanto aos retrocessos, estes podem ser pontuais, limitados a momentos. O que traz maior entrave ao desenvolvimento desse trabalho é o movimento, sempre presente, de retorno a uma condição anterior, menos trabalhosa, na qual predominam: a nãointegração (em todos os sentidos - interna às unidades curriculares, entre os docentes, a Universidade e serviços de saúde e entre os cursos); o desenvolvimento de atividades práticas somente no HU; retorno às atividades predominantemente teóricas;isso para citar apenas os aspectos mais significativos e que representam obstáculos a serem superados no dia a dia. Esse movimento tem muitas explicações, dentre as quais se destaca a inserção da maior parte dos docentes, no seu cotidiano, em serviços hospitalares, nos quais desenvolvem suas atividades de assistência e pesquisa. A compreensão que se tem é que a preceptoria direta do estudante não se faz sem a presença do docente, ainda que possa contar com profissionais dos serviços em situações muito especiais - concordância do profissional, do gestor, continuidade, integração com a equipe da Universidade. Na atual situação da Região Metropolitana de São Paulo, essas condições são raras e o que se observa, em geral, é o nãointeresse do profissional, a nãoconcordância do gestor (devido à produtividade) e a descontinuidade, pois há muita rotatividade de profissionais na rede de serviços da Atenção Básica. Todos esses aspectos estão interligados, já que um contingente expressivo dos profissionais não tem a intenção de permanecer nesses serviços; trata-se de uma atuação transitória que precede a residência médica (no caso dos médicos) ou cursos de especialização (demais profissionais). Assim, a participação de profissionais dos serviços de saúde na supervisão do estudante se faz parcialmente em uma unidade curricular do curso médico (Saúde Coletiva IV - Práticas Ambulatoriais/Medicina Preventiva - 5ª série) e em algumas unidades curriculares da Enfermagem.

As dificuldades de implementar as atividades externas ao HU não se devem ao nãoreconhecimento da necessidade de ampliar os cenários de práticas. Gestores dos cursos e docentes identificam esse problema.Está claro que a organização da graduação inclui o serviço universitário, ou seja, parte da assistência do HU pode e deve constituir cenário de prática para a graduação, masse sabe que isso não é suficiente. São necessários serviços ambulatoriais - atenção básica e secundária; serviços de urgência/emergência (nem todos os HUs estão localizados ou representam referência para trauma, por exemplo); serviços hospitalares organizados em grandes áreas clínicas e cirúrgicas (pediatria, clínica, ginecologia, obstetrícia, cirurgia); serviços de saúde mental (Caps-álcool, drogas, infantil, por exemplo). A operacionalização dessas atividades é bastante trabalhosa e apresenta momentos de avanços e retrocessos. Somam-se a essas dificuldades as concepções dos estudantes em relação às atividades, em geral, pouco motivadoras.

Assim, a gestão do curso tem que dar conta de organizar essa estrutura para o ensino e, ao mesmo tempo, identificar professores/profissionais que possam desenvolver a preceptoria de forma contínua, para que de fato ocorra um aprendizado e um aprimoramento do curso. Todo o processo é dinâmico, e são necessários ajustes e a apreensão de novas demandas em saúde. Essa atividade requer dedicação, envolvimento; porém, há outras cobranças na avaliação do docente e que dizem respeito à sua carreira na Universidade, sobretudo, o desenvolvimento de pesquisas e atuação na pós-graduação. Nesse sentido, é fundamental que os processos de avaliação (MEC/Inep) dos cursos e da instituição também considerem esses mesmos parâmetros previstos nas DCNs, para que haja um reforço a essas ações. Caso contrário, esse movimento de ensino para fora do HU, já bastante difícil, não terá sustentação.

Nos serviços de saúde, os retrocessos dependem das políticas, dos gestores e do envolvimento destes no processo de consolidação do SUS e do direito à saúde. A cada mudança dos dirigentes da saúde - sejam eles o próprio prefeito, o gestor ou o gerente, são definidas novas prioridades, estabelecidos novos pactos. Quando há compromisso com os princípios do SUS e empenho na garantia dos direitos à saúde, reconhecimento da cidadania e convergência nos planos e estratégias, a articulação é mais favorecida, os avanços são mais evidentes, mesmo que de início sejam necessários ajustes. Em outros momentos, há divergências, projetos são interrompidos ou redirecionados.

\section{Dificuldades e Pontos Críticos - os Desafios dos Serviços na Região Metropolitana de São Paulo}

É fundamental uma compreensão da situação do SUS na Região Metropolitana de São Paulo, em especial da cidade de São Paulo, para que se possa dimensionar as dificuldades e os pontos críticos. Considera-se como rede de serviços os estabelecimentos de saúde que efetivamente estão integrados aos projetos Pró-Saúde da Medicina, Enfermagem e Fonoaudiologia. Os serviços estão vinculados às Secretarias Municipais de Saúde (SMS) dos municípios de Embu, São Paulo e Diadema (este último integrado em 2009). Essa nova articulação com o município de Diadema foi motivada por alguns fatores: 
presença de um campus da Unifesp com curso de Farmácia e parcerias em andamento (ainda que de início tenha ocorrido informalmente); proximidade com o campus São Paulo da Unifesp; sistema local de saúde bem consolidado e que dispõe de rede com diferentes níveis de atenção à saúde; dificuldades e limitações de atuação no município de São Paulo, em função do modelo de gestão (contratação de Organizações Sociais de Saúde para cada território e para diferentes serviços, perdendo-se a organização como sistema, com continuidade) e de assistência adotados (redução da área física de Unidades Básicas de Saúde e transformação em ambulatórios médico-assistenciais - AMA).

O cenário de (des)construção do Sistema Único de Saúde (SUS) na cidade de São Paulo, com o repasse da gestão hospitalar e da rede de atenção básica para as Organizações Sociais de Saúde (em pedaços da cidade), tem sido apontado como um dos principais entraves para a efetivação das propostas previstas nos projetos Pró-Saúde, os quais visam a uma integração que poderia levar a uma maior qualificação da atenção à saúde. Sem dúvida, essa situação impacta, também os processos de implantação das transformações curriculares, pois dificulta uma maior adesão dos professores e dos estudantes à proposta do Pró-Saúde, que tem no SUS o seu principal espaço de ensino-aprendizagem.

A entrega da gestão municipal para entes privados (Organizações Sociais de Saúde-OSS) estabelece contratos de gestão que têm no controle de metas, isto é, de produtividade da assistência, a sua principal âncora para o repasse financeiro. Esse quadro faz com que vários profissionais da rede, nas quais os estudantes desenvolvem parte de suas atividades didáticas, questionem sobre a pertinência ou não de se envolver, de fato, com as propostas de integração. Em princípio, percebe-se um grande interesse por boa parte das equipes que estão nas UBSs em receber os estudantes, mas esse interesse vem diminuindo no dia a dia em função de uma cobrança pelos números de produtividade, seja por parte da OSS parceira ou da SMS-SP). Ambas não assumem a articulação da universidade com os serviços de saúde como um potente instrumento de qualificação da própria produção de saúde. Esse modelo de gestão traz um agravante em relação à interlocução universidade/ serviço de saúde, uma vez que os representantes da Secretaria Municipal na Comissão de Acompanhamento Local não possuem governabilidade sobre o território, pois este está sob a administração de OSSs, as quais estabelecem seus contratos diretamente com a prefeitura do município.

As consecutivas mudanças na estrutura organizacional e administrativa da SMS-SP, que nos últimos oito anos passou por três diferentes arranjos organizacionais, os quais incluem, por exemplo, mudanças de território e da função de cada uma das instâncias da estrutura organizacional, associada a uma desqualificação do próprio Conselho Municipal de São Paulo, agravam o quadro no município. Aliado a essa situação é possível verificar, ainda, um modelo técnico-assistencial para a cidade que varia de governo a governo, e dentro dos próprios governos, sem uma continuidade e/ou uma avaliação do processo. Exemplo disso é a entrada do Ambulatório Médico Assistencial (AMA)12, que vem se constituindo em um conjunto extenso de serviços de pronto-atendimento na cidade, retorno à consulta desqualificada tipo "queixa-conduta", uma prática assistencial tão criticada nos anos 1970, com reduzida articulação com os outros níveis de atenção à saúde. Estudo concluído em 2008 (parceria entre a Faculdade de Saúde Pública da USP e a Unifesp, intitula do Análise de um indicador de monitoramento dos serviços de atenção básica de saúde em diferentes modelos assistenciais - Edital $\mathrm{MCT} / \mathrm{CNPq}$ - MS/DAB/ SAS №049/2005)13, sugere que esses serviços possivelmente absorvem uma demanda sensível aos cuidados na atenção básica e que os AMAs apresentam discutível capacidade de articulação e continuidade dos cuidados. Esse quadro complexo do município de São Paulo vem aprofundando a dificuldade à constituição de cenários de ensino-aprendizagem, nos quais os princípios e a diretrizes do SUS efetivamente estejam sendo construídos e fortalecidos. Houve, ainda, um movimento de resistência pelo segmento de usuários em relação à implantação dos AMAs na região, com perda de espaço físico das próprias UBSs.Porém o processo tem sido difícil e se enfraquece com a proposta das Unidades de Pronto-Atendimento - UPAs, que ganhou maior evidência no ano de 2010 e se estende para os demais municípios da Região Metropolitana de São Paulo e do País como um todo.

Assim, princípios e estratégias do SUS, tão debatidos e discutidos com os alunos, com destaque à integralidade, continuidade dos cuidados, conceito ampliado de saúde, intersetorialidade, descentralização e controle social, tornam-se teóricos, pouco atingíveis. A realidade do modelo assistencial e a própria legislação, contraditoriamente, apontam outra direção. Os financiamentos definem, centralmente, as ações em detalhes, considerando pouco a experiência já desenvolvida nos municípios.Com as OSSs e os contratos de gestão, o papel dos conselhos de saúde está cada vez mais limitado, colocando em xeque o controle social (Portaria no 1.034/MSGM/2010 - DOU de 19/05/2010, que dispõe sobre a participação complementar das instituições privadas com ou sem fins lucrativos de assistência à saúde no âmbito do SUS).

No município de Embu, onde em 2009 completou-se 40 anos de atividades, a articulação está bem consolidada, há con- 
vênio estabelecido e assinado, o qual é renovado a cada 5 anos. Nesse longo período, houve momentos de maiores dificuldades, as quais têm sido superadas por meio da participação nas instâncias de decisão do município, em especial no Conselho Municipal de Saúde. Atualmente, o município também conta com diferentes OSSs, as quais administram uma maternidade (partos de baixo risco), um hospital geral do estado (partos de médio e alto risco), serviços diagnósticos e equipes de PSF. Em relação à experiência recente,em Diadema, ainda não se pode fazer um diagnóstico, pois ela é difícil de ser analisada. Nesse momento, apresenta grande convergência de ideias e encontra-se em processo de construção.

Um ponto crítico que deve ser ressaltado, e que é comum a todos os municípios, refere-se à área física dos serviços de saúde.As unidades básicas são de pequenas dimensões, muitas em imóveis adaptados, sendo improvisadas, o que não atende à necessidade assistencial e, menos ainda, a de ensino. Não há consultórios ou espaços para as atividades dos alunos que são mais morosos, considerando que todas as ações devem ser supervisionadas pelo preceptor. É muito difícil defender a importância desse atendimento se as condições são inadequadas. O descontentamento do profissional/docente é evidente, e isso é passado para o aluno, que dificilmente considerará esse local para seu futuro exercício profissional. Por outro lado, os serviços hospitalares e as unidades de pronto-atendimento, além de mais atrativas do ponto de vista financeiro e de regime de trabalho, apresentam condições mais adequadas, maiores recursos. Em recente deliberação da CIB/São Paulo (DOE, 26/05/2010), dentre outras questões, a inadequação da área física é destacada, pois "reforça a ideia de unidades simplificadas para exercício de uma medicina simplificada, muitas vezes confundida como desqualificada, voltada para uma população destituída de direitos". A deliberação destaca a importância dessa questão e, que ela requer esforços visando à superação.

\section{Dificuldades e Pontos Críticos - os Desafios na Universidade Federal de São Paulo}

A Unifesp, antiga Escola Paulista de Medicina, transformou-se em universidade em 1994. Porém, foi a partir do processo de expansão (2005) que efetivamente passou a se colocar como tal. De cinco cursos e um campus em 2004, restritos à área da saúde, a Unifesp, em 2010, passou a tercinco campi, 29 cursos nas áreas de biológicas, humanas e exatas. Além disso, vocacionada para programas de pós-graduação, a Universidade no campus São Paulo, hoje, tem cerca de 1.300 alunos na graduação, aproximadamente 4.000 alunos de pós-graduação lato sensu (800 médicos residentes) e mais de 3.000 alunos de pós-gra- duação stricto sensu. É nesse contexto que se dá a discussão da graduação e dos projetos Pró-Saúde. Se essa estrutura por um lado traz muitas possibilidades;por outro, há necessidade de inserir a graduação também como ponto importante nas atividades dos docentes, o que constitui permanente desafio. Desde 2005, uma comissão de distribuição de vagas docentes para os departamentos tem considerado a carga horária na graduação como importante critério a ser incluído e, nos concursos, verificou-se que alguns editais prescreveram que as atividades no ensino, extensão e pesquisa deveriam ter o mesmo peso na análise do memorial. As Diretrizes Curriculares Nacionais e o processo de elaboração dos projetos Pró-Saúde contribuíram para identificação de fragilidades e necessidades de mudanças, as quais, nesse contexto da instituição, não são simples.No entanto, verificou-se que foi possível obter avanços. As ações para superar essas dificuldades, que não são exclusivas da Unifesp, mas certamente são muito significativas na instituição, devem ser contínuas.Não há um único caminho, e todas as ações devem ser discutidas, pactuadas.

\section{Potencialidades, Perspectivas e Sustentabilidade}

Considera-se que o maior ganho foi a articulação entre os cursos e a definição de territórios comuns de atuação nos municípios de São Paulo, Embu e Diadema e a existência de convênios. A criação da Comissão de Acompanhamento Local e sua articulação com as comissões/núcleos de cada município e comissões de curso constitui um espaço democrático para discussão e de união de esforços junto à Universidade e aos serviços de saúde. Dificuldades e avanços são compartilhados e há um grande aprendizado. Algumas estratégias, em especial os encontros Universidade/serviços de saúde, realizados anualmente, mostraram o potencial para aproximações, ajustes e redirecionamentos.

\section{Ensino na Graduação}

Os recursos do Pró-Saúde têm contribuído muito e proporcionaram uma adequação em relação a equipamentos (computadores, projetores, armários nas unidades, cadeiras, macas, equipamentos específicos) e também para assessoria e apoio de professores em eventos de educação emsaúde. O eixo da saúde coletiva desenvolvido no curso médico e a assessoria para as mudanças curriculares nos cursos de Enfermagem e Fonoaudiologia também contaram com auxíliodo Pró-Saúde. Entretanto, as atividades de ensino nas unidades, no momento, não dependem dos recursos do Pró-Saúde, ou seja, a sustentabilidade está assegurada pelaUniversidade. $\mathrm{O}$ transporte de alunos foi garantido a partir da definição de alguns critérios (reside em outro município, há dificuldade de acesso a trans- 
porte coletivo na proximidade do serviço, etc.). As comissões de ensino de todos os cursos entendem que os currículos devem ser dinâmicos e estão em permanente desenvolvimento para acertos, redirecionamentos. Todas as comissões têm desenvolvido seminários e oficinas, visando ao aprimoramento do currículo e dos processos avaliativos.

O tema graduação está mais presente nas instâncias de decisão da IES, constituindo, inclusive, critério para distribuição de vaga docente entre os departamentos e concursos. Permanecem, entretanto, dificuldades (já apresentadas anteriormente) que são superadas em alguns momentos e, considerando a complexidade da instituição e dos serviços de saúde com os quais se estabelecem as parcerias, apresentam também retrocessos. É um processo que requer contínua discussão, reforços e, portanto, deve se inserir nas instâncias formais - comissão de curso epró-reitorias, para que tenha sustentação.

\section{Educação Permanente e Pesquisa}

Em relação à Educação Permanente/Pesquisa, a decisão do Conselho de Extensão de estabelecer duas vagas para todos os cursos lato sensu e a abertura de ambulatórios ou serviços para capacitação de profissionais representa um passo importantíssimo da Universidade diante do SUS, cumprindo de fato seu papel. Soma-se a essa iniciativa a participação nos demais projetos do próprio MS/SGETS, como o Unasus. O programa de residência multiprofissional também foi elaborado considerando esses cenários de práticas, sendo, portanto, integrado ao ensino da graduação.

Há ainda grande expectativa em relação à recente comissão criada pelo Conselho de Pós-Graduação visando a estimular a elaboração de projetos de pesquisa de forma articulada aos profissionais dos serviços e a partir das demandas locais. Vale lembrar que muitos profissionais já estão inseridos em programas de pós-graduação stricto sensu,o Mestrado Profissional (Medicina Preventiva) para profissionais do município de Diademase encontra em fase de elaboração.

\section{Serviços de Saúde - Perspectivas}

A Região Metropolitana de São Paulo apresenta uma condição bastante complexa - trata-se de grande centro urbano, com mais de 18 milhões de habitantes, com extensa rede de serviços de saúde que recebe pessoas de todo o estado de São Paulo e do País. Há um diversificado mercado de trabalho público e privado na área da saúde que, como apresentado anteriormente, oferece muitas possibilidades. O modelo de gestão (mais de dezOSSs administram partes do território do município de São Paulo e de outros municípios da Região Metropolitana) e o modelo assistencial (ampliação dos serviços de pronto-atendimento) trazem contradições que dificultam o cumprimento dos princípios do SUS, em especial o controle social e a integralidade (esta em todos seus sentidos - da atenção à pessoa, interna a cada serviço, entre diferentes níveis de complexidade). É nesse cenário que se desenvolve o ensino da graduação da Unifesp e de outras instituições de ensino da Região Metropolitana. As atividades práticas, a problematização e a inserção dos alunos nos serviços de saúde desde o início do curso visam ao aprendizado do funcionamento do SUS, seus princípios e estratégias, refletindo, sobretudo, sobre o direito à saúde, sobre a cidadania. Ainda que a abrangência e a qualificação do direito à saúde sejam conceitos em permanente disputa, e isso também faz parte do aprendizado, a realidade dos serviços, principalmente no município de São Paulo, tem apresentado retrocessos importantes comprometendo a assistência e, consequentemente, o ensino nas profissões de saúde.

As perspectivas vão depender dos rumos políticos da saúde. O modelo das OSSs tem se difundido, ainda que constitua opção polêmica nos seus fundamentos jurídicos e políticos em relação à sua obediência legal, à sua efetiva superioridade sobre a administração pública e às repercussões que essa alternativa terá em fraudar ou não o princípio fundamental da política de saúde, qual seja: a saúde como direito social, como política de Estado, universal, integral, igualitária e aberta ao controle social.

\section{CONSIDERAÇÕES FINAIS - ALGUNS RESULTADOS POSITIVOS}

O Promed e o Pró-saúde constituem políticas indutoras de mudanças curriculares na formação dos profissionais de saúde da maior importância, na medida em que tratam de uma atuação interministerial, diferindo, portanto, das políticas anteriores. Para os cursos da Unifesp, constituiu grande reforço ao processo de mudança que vinha se desenvolvendo. São muitos os fatores que influenciam a estruturação e operacionalização dos cursos, muitos deles externos à IES. Assim, é imprescindível clareza na identificação desses fatores, compreendendo-se os limites e possibilidades dessas mudanças e seu papel na consolidação do SUS, hoje sofrendo um processo de desfinanciamento, ampliação da participação dos serviços privados na execução das atividades e esvaziamento das instâncias de controle social (conselhos locais, municipais e estaduais). No desenvolvimento das atividades de ensino, assistência e pesquisa, essas e outras questões decorrentes do cotidiano da atuação dos alunos nos serviços de saúde acabam por ser também objeto de discussão e aprendizado.No entanto, está claro o difícil momento e a complexidade de conflitos e interesses que ameaçam os princípios do SUS e o direito à saúde em nosso país. 


\section{REFERÊNCIAS}

1. Brasil. Ministério da Educação. [homepage]. [acesso em 19 set. 2010]. Disponível em: . http: / / portal.mec.gov.br/ index.php?option=com_content\&view $=$ article\&id=12991: diretrizes-curriculares-cursos-de-graduacao

2. Brasil. Ministérios da Educação e da Saúde. Portaria Interministerial nº610. Promed. Brasília (DF), em 26 de março de 2002.

3. Brasil. Ministérios da Educação e da Saúde. Portaria Interministerial no2.101, de 3 de dezembro de 2005. Institui o Programa Nacional de Reorientação da Formação Profissional em Saúde - Pró-Saúde - para os cursos de Medicina, Enfermagem e Odontologia. Brasília (DF), 2005

4. Brasil. Ministérios da Educação e da Saúde. Portaria Interministerial nº2.101, de 3 de dezembro de 2005. Programa Nacional de Reorientação da Formação Profissional em Saúde - Pró-Saúde. Objetivos, Implementação e Desenvolvimento Potencial. Brasília (DF), 2007.

5. Puccini RF, Andreazza R. O Promed e o Pró-Saúde na Unifesp: contribuições para o aprimoramento do projeto pedagógico. In: Puccini RF, Sampaio LO, Batista NA. A formação médica na Unifesp - excelência e compromisso social. São Paulo: Editora Unifesp, 2008; p.71-99.

6. Andreazza R, Arantes LSR, Fiorini-Puccini R. A (re)construção do cenário de aprendizagem no território da Coordenadoria Regional de Saúde de São Paulo: o desafio do Núcleo de Articulação Universidade-Serviços de Saúde do Pró-Saúde Medicina e Enfermagem da Unifesp. In: Anais do 45ํㅡㄹ Congresso Brasileiro de Educação Médica, Uberlândia (MG), 2007. Revista Brasileira de Educação Médica, 2007.

7. Arantes LSR, Fiorini-Puccini R, Andreazza R. A experiência dos estudantes com o controle social do SUS na construção do cenário de aprendizagem dos cursos de graduação da Unifesp. In: X Congresso Paulista de Saúde Pública, 2007. Anais Eletrônicos do X Congresso Paulista de Saúde Pública -Revista Saúde \& Sociedade, 2007.

8. Jacinto SCG, Hayashida MZ, Ávila CRB, Gabrielloni MC, Lacaz FAC, Puccini RF. A produção científico-acadêmica da Universidade Federal de São Paulo - Campus Vila Clementino: contribuições para a consolidação do Sistema Único de Saúde. Uma análise embasada nos programa de pós-graduação lato e stricto sensu. Relatório Final. Iniciação Científica - CNPq, 2010. Anais do XVIII Congresso de Iniciação Científica da Unifesp. São Paulo (SP), 2010.

9. Hayashida MZ, Jacinto SCG, Puccini RF, Ávila CRB, Gabrielloni MC, Lacaz FAC. A produção científico-acadêmica da Universidade Federal de São Paulo - Campus Vila Clementino: contribuições para a consolidação do Sistema Único de Saúde. Uma análise a partir dos periódicos indexados. Relatório Final. Iniciação Científica - CNPq, 2010. Anais do XVIII Congresso de Iniciação Científica da Unifesp. São Paulo (SP), 2010.

10. Andreazza R, Fiorini-Puccini R, Arantes LSR, Puccini RF. Encontro universidade-serviços de saúde: a experiência dos cursos de graduação da Unifesp. In: Anais do $45^{\circ}$ Congresso Brasileiro de Educação Médica, Uberlândia (MG), 2007.

11. Puccini RF, Jorge MR. O plano político pedagógico do curso de Medicina: um processo em permanente construção. In: Puccini RF, Sampaio LO, Batista NA. A formação médica na Unifesp - excelência e compromisso social. São Paulo: Unifesp;2008.p. 119-59.

12. Puccini PT. As unidades de assistência médica ambulatorial (AMA) no município de São Paulo, Brasil: condições de funcionamento e repercussões para atenção básica no Sistema Único de Saúde. Cad Saúde Pública. 2008;24: 2755-66.

13. Cornetta VK, Puccini PT, Puccini RF, et al. Relatório Final Análise de um indicador de monitoramento dos serviços de atenção básica de saúde em diferentes modelos assistenciais - Edital MCT/CNPq - MS/DAB/SAS No049/2005), 2008.

\section{CONTRIBUIÇÃO DOS AUTORES}

Todos os autores participaram forma suficiente na concepção e desenho deste estudo, da análise e interpretação dos dados assim como da redação deste texto.

\section{CONFLITO DE INTERESSES}

Declarou não haver.

\section{ENDEREÇO PARA CORRESPONDÊNCIA}

Rosana Fiorini Puccini

Rua Botucatu, 598 - Vila Clementino

São Paulo

CEP. 04023-062 SP 